\title{
SOBRE LA SUPUESTA DESPRONOMINALIZACIÓN DEL RELATIVO
}

\author{
RAMÓN TRUJILLO \\ Instituto de Lingüística «Andrés Bello» \\ (Universidad de la Laguna)
}

Posiblemente no exista ninguna disciplina tan dogmática y poco crítica como la gramática. El peso de la realidad significada por las expresiones, de una parte, y el de las categorías conceptuales establecidas por la tradición, de otra, suelen dar, como resultado, enfoques que nada tienen que ver con la intuición idiomática de los hablantes, la cual debe ser sin duda el único y verdadero objeto de esta disciplina. Todo lo que no sea el análisis de una forma o de una construcción en lo que tiene de único y peculiar, en lo que tiene que ver con la manera de ser sentida e interpretada en una lengua dada, no sólo es metafísica, como suele decirse a veces, sino, con frecuencia, pura charlatanería. Con frecuencia vemos a los gramáticos afanarse en establecer categorías inexistentes, confundiendo la estructura e, incluso, el significado idiomáticos con la forma propia de los procesos reales denotados por la lengua: es lo que sucede con la cuestión de la reflexividad española: no acaban de entender que la diferencia entre se afeita y se va es léxica y que sólo tiene que ver con la naturaleza misma de los procesos designados, pero jamás, y de ninguna manera, con el significado o con la estructura gramatical de ambas expresiones, que es la misma para cualquiera que sepa que el significado de una palabra o de una expresión no se confunde con ninguna de sus interpretaciones concretas posibles. La interpretación corresponde al plano de los acontecimientos; el significado, al del idioma.

Pero las confusiones no sólo se dan en el plano del conflicto entre lengua y realidad, sino también (y mucho más gravemente) en el del conflicto entre lengua y tradición gramatical. Ya advertía Bello, en el prólogo de su Gramática, contra este tipo frecuente de errores que consisten en atribuir a una lengua las categorías y las propiedades de otra. En efecto: si no estuviésemos bajo el peso de la tradición grecolatina, ¿a quién se le ocurriría distinguir un que «pronombre 
relativo» de otros que no equivalentes al qui? Es evidente que, de no haber existido tal modelo, lo que hoy es distinción entre diversos que no habría salido nunca de los límites estrictamente sintácticos entre los diversos tipos de subordinadas, ya que, por ejemplo, la diferencia entre un que «relativo» y un que de otra clase no tiene nada que ver con la naturaleza propia de esta partícula, sino con el hecho de que el antecedente tenga o no una segunda función con el verbo de la subordinada: por eso es adjetiva la que aparece en «este es un libro con el que te partes de risa» y no lo es la de «este es un libro que te partes de risa», pues, en esta última, al contrario que en la anterior, libro no tiene nada que ver con partes, por lo que tiende a sentirse como consecutiva, con independencia del que quiera seguir viendo una oración adjetiva con preposición elidida: pero, ¿quién podría decir definitivamente si es lo uno o lo otro, cuando resulta incluso posible entender ambas cosas en forma simultánea (i.e. tal... que o con... que)?

Pero no sólo consiste el mal en la distinción artificiosa e irreal entre un pronombre y otras cosas diferentes, sino en algo aún peor: en la creencia, absolutamente infundada, de que ciertas palabras, los pronombres, se «llenan» con el contenido de otras, a las que «sustituyen». Es un prejuicio de la tradición gramatical, pero - hay que confesarlo- de los menos inteligentes. Lo primero que hay que tener en cuenta es la verdad idiomática de que ningún signo asume el significado de otro, lo que no impide, particularmente entre los determinantes, que la determinación sea anafórica o catafórica: en «vino con su amiga y con ésta se volvió», ésta no «sustituye» a amiga ni significa 'amiga': lo único que significa ésta es ese tipo de determinación espacial que posee siempre el demostrativo, con independencia de que recaiga por razones puramente contextuales sobre amiga. De la misma manera, sería disparatado afirmar que, en «vi un libro y lo compré», lo reproduce a un libro o toma el significado 'un libro': lo significa el mismo grado de determinación que posee el artículo (del cual es variante), y, por tanto, el que se le atribuye en relación con el segundo verbo $^{1}$. En todo caso podríamos decir que ese $l o$ es lo mismo que el $e l$ que aparecería si dijéramos «vi un libro y compré el libro», expresión en la que el tampoco sustituye nada, sino que significa un grado de determinación diferente al de un, razón por la cual, además, resulta doblemente disparatado decir que $l o$ reproduce un libro o que posee ese mismo significado: si hubiéramos dicho «vi un libro y compré uno», está claro que reproduciríamos el mismo grado de indeterminación del «antecedente», por lo que entenderíamos que la segunda referencia no tiene por qué apuntar al mismo objeto que la primera, al revés de lo que sucede con lo o con el artículo.

Nada más desacertado que ese concepto de reproducción semántica que ha dominado siempre en la tradición gramatical. Un signo puede aludir contextualmente a otro, pero no sustituirlo, ni significarlo, ni repetirlo: ése es un principio básico de la semántica: ninguna palabra toma ni puede tomar el

\footnotetext{
' Cfr. mi «La cuestión del artículo en español», en Verba, 14, 1987.
} 
significado de otra. En «llegó el otoño y con éste las clases», éste no es el otoño, sino una determinación que en este contex to alude a él; ni en «de las dos muchachas, la guapa era su hermana», guapa sustituye a muchacha, ni está en su lugar, ni significa lo mismo: guapa no deja de ser adjetivo porque aparezca en la distribución de un nombre, pues su naturaleza categorial se define precisamente por su relación con un nombre, independientemente de que esté expreso o no. De ahí que no haya error mayor que esa noción metafísica de reproducción semántica o categorial. Ni siquiera las partículas relativas reproducen nada, aunque sus significados incluyan la idea de la relación con un antecedente: pero no es lo mismo aludir a un antecedente que reproducirlo: es evidente, por ejemplo, que que alude a perro en "perro que ladra no muerde», pero ya no lo es tanto que lo «reproduzca», como si dijéramos que tal expresión es la suma de «perro no muerde» y de "perro ladra», cosa que si bien puede ser cierta considerando las circunstancias reales denotadas por el ejemplo, no lo es en absoluto considerándolo en su ser idiomático, en el que nadie siente esa absurda superposición oracional que resulta de un análisis no lingüístico (sino lógico o pragmático) de la secuencia.

Pero el triple prejuicio «pronominal» de la sustitución, de la reproducción semántica y de la repetición del mismo signo bajo formas diferentes, sigue siendo todopoderoso en gramática, y cuesta pensar en la posibilidad de una consideración de los hechos idiomáticos como idiomáticamente son, en lugar de imaginar tanta fantástica operación para explicarlos, no en su verdadero ser, sino mirándolos como trasuntos de los procesos físicos o mentales que ocasionalmente puedan representar.

$* * *$

Voy a detenerme ahora en un típico ejemplo de interpretación gramatical: el del llamado pronombre relativo y el de su presunta función nominal, puesto que se le supone reproductor «absoluto» de nombres antecedentes. Y es precisamente porque se le supone esa entidad nominal en el seno de la oración subordinada por lo que la aparición de nuevos pronombres o determinantes alusivos al antecedente hace soñar a los gramáticos con «duplicaciones» y con «despronominalizaciones», es decir, con la pérdida de la función «repetidora», que en tal caso aparecería menoscabada o suprimida. Todo se basa en la suposición sorprendente de que el relativo sufre alguna mutación, por ejemplo, en «tienes unas manías que no te las puede aguantar nadie»: partiendo de la sacrosanta pero absurda hipótesis de que ese que «repite» a unas manías, se podría llegar con facilidad a imaginar esta extraña estructura «básica» para la cláusula de relativo: «nadie te las puede aguantar unas manías». Es evidente que la hipótesis o la suposición de que, en «que no te las puede aguantar nadie», se repite el complemento directo puede llevar a dos soluciones ingenuas del problema: o hay pleonasmo sin más, o uno de los presuntos complementos directos deja de 
serlo. Soluciones ingenuas, en verdad, pues ambas carecen en absoluto de fundamento.

Para empezar, la «anomalía» de «que no te las puede aguantar nadie» proviene de la poco meditada creencia en el carácter nominal y reproductor de que. Si partimos de la hipótesis, absolutamente indemostrable, de que ese que es un sustantivo en función de complemento directo, obviamente las se transforma en una duplicación suya, con lo que, además, se «aflojan» los lazos existentes entre la cláusula adjetiva y el antecedente al que modifica (unas manías). Pero, en primer lugar, la anomalía no es real, ya que tales construcciones han sido habituales en todas las épocas de la lengua y en todos los estilos y registros: hablar de anomalía en este caso no es más que el resultado de haber dado por buena una interpretación de los hechos que no se adapta a la realidad. Se inventa una hipótesis insostenible y luego se declara «anómalo» sin más todo lo que entra en conflicto con ella. Para comprender el significado de las referencias anafóricas (pronominales o no) en las oraciones de relativo, lo primero que tenemos que hacer es examinar la naturaleza de esas partículas, su valor semántico y su función sintáctica, pues sólo así sabremos si realmente la aparición de pronombres anafóricos referidos al antecedente alteran o no de verdad la naturaleza del relativo.

Ya hemos visto que el concepto de reproducción semántica, y, en consecuencia, el de sustitución, no se corresponden con ningún punto de vista realista sobre el lenguaje. Es un principio básico de semántica y, por tanto, de gramática, el de que ningún signo, incluidos todos los llamados pronombres, sustituye nada, y el de que cualquiera de ellos sólo puede aparecer en lugar de su propio significado. Pero este principio no significa, sin embargo, que un signo dado no pueda servir, en un determinado contexto, para hacer referencia a otro u otros, tanto en relación con una mención anterior, como con una posterior. Es éste un papel común en todos los signos de función restrictiva, como sucede con los determinantes, cuyo papel consiste en marcar una situación en el universo del discurso, o con los adjetivos, cuya función no es otra que la de determinar al nombre, mediante la agregación de nuevas propiedades semánticas. Pues bien: tanto esas propiedades semánticas que sólo se pueden realizar en los nombres, como esas situaciones posibles en el universo del discurso, pueden estar referidas a nombres sobrentendidos o mencionados previamente, sin que haya que suponer que, en tales situaciones, unas palabras sustituyen a otras o están en lugar de ellas ${ }^{2}$. Esta es la cuestión esencial: es absolutamente inexacto considerar que esta o guapa son sustantivos o están sustantivados en «ésta (o

\footnotetext{
${ }^{2} \mathrm{Ni}$ siquiera el artículo usado en función primaria con valor de persona puede considerarse seriamente como un sustituto: una cosa es que, en «el que a hierro mata, a hierro muere», $e l$ se interprete como 'la persona', y otra, que posea tal significado, aunque estemos habituados a interpretar así todo artículo no anafórico que figure como antecedente del relativo. Los hábitos idiomáticos hispánicos presuponen la anáfora cuando la referencia de persona es imposible, por lo que no se diría sin este tipo de mención «el que sea inflamable debe mantenerse lejos del calor». Pero esto no contradice lo dicho, pues, en todo caso, el significado de el es el de la determinación de lo consabido,
} 
«la guapa») es su hermana»: tanto el determinante, como el adjetivo, mantienen íntegramente sus respectivas condiciones categoriales y no son, por tanto, nombres, ni están en lugar de nombres, sino determinando nombres que, por alguna razón, no se expresan.

Y lo mismo, exactamente, sucede con el relativo, que, dicho sea de paso, es también un determinante: el que de «perro que ladra no muerde» determina, acota o precisa el alcance que debe atribuirse a su antecedente perro, pero sin repetir ese nombre ni el contenido de ese nombre en la cláusula que encabeza. En lugar de representar la inverosímil operación lógica de «sumar», como dije antes, «perro no muerde» y «perro ladra», ya de por sí también inverosímiles, lo que sucede realmente es que ese que facilita la doble referencia funcional del determinado, vinculándolo con dos verbos. La única objeción a este punto de vista, con visos de seriedad al menos en principio, sólo se relaciona con un problema secundario que no tiene que ver más que con cuestiones de sintaxis superficial o, si se quiere, meramente distribucionales. En efecto: el hecho de que las marcas formales de la «segunda» función del antecedente aparezcan justamente delante del relativo parecen argumentos serios a favor de la condición nominal de éste. Si se considera un ejemplo como «he visto en Madrid una casa en la que vivió Cervantes», parecerá incontrovertible, al menos a primera vista, la alegación de que sólo un nombre o un elemento de naturaleza nominal puede ser modificado por el artículo o aparecer como término de una preposición. El argumento es de peso y debe ser considerado detenidamente.

Son verdades recibidas, desgraciadamente sin discusión, las de que el artículo se antepone siempre a un sintagma nominal o de valor nominal $y$ de que también la preposición se antepone siempre a un nombre o a una expresión nominal. $Y$ estas «verdades» se han mantenido siempre firmes como rocas, a pesar de evidencias en contra, como sucede en el caso de la rección preposicional de adjetivos, en ejemplos del tipo «presume de discreta», o de preposiciones que no aparecen antepuestas a sus términos verdaderos, como pasa en ejemplos del tipo «sé al blanco que tiras», en que la preposición no corresponde a la "primera» función de blanco, es decir, a su función con sé, sino a la «segunda», es decir, a la que contrae con tiras. Una visión mecanicista (o distribucional) de la gramática ha confundido tradicionalmente las categorías y las funciones propiamente idiomáticas con su disposición física en el discurso, motivada por cuestiones que en ocasiones tienen más que ver con la fonología, e incluso con la psicología, que con la propia gramática: ahí están, por ejemplo, las diferencias físicas entre ellas y las, que aunque no son más que el resultado histórico de cuestiones puramente fonosintácticas, producen la falsa impresión de que puede no existir la identidad semántica que observamos entre ellos ${ }^{3}$; y ahí están

por lo que se dirá que equivale a «la persona que», pero no a «una persona que» o a otro grado de determinación cualquiera. El hecho de que lo consabido, sin anáfora, sea en este caso siempre la persona no parece más que el punto de vista propio de una psicología social determinada.

${ }^{3} \mathrm{Cfr}$. «La cuestión del artículo en español», ya citado. 
también las vacilaciones en lo que se refiere al término de las preposiciones en las oraciones adjetivas: «no ignoro con la gente que andas» es incluso más esperable que la supuestamente correcta «no ignoro la gente con que andas ${ }^{4}$, aunque la preposición se refiere, no a la «primera» función de gente (objeto directo), sino a la segunda, lo que parece secundario frente al hecho de que gente es simultáneamente término sin preposición de una relación con ignoro y término con preposición de una relación con andas: al ser gente término simultáneo de dos relaciones sintácticas, no es de extrañar la vacilación en la colocación física de las marcas, con independencia de que el lenguaje literario haya preferido siempre la posposición de la preposición de la segunda función a su término, para jerarquizar el orden de éstas. Lo que no podrá hacerse nunca es hablar, como se hace, de una anomalía que consiste en que el antecedente «atrae» una preposición que le corresponde al relativo, porque, simplemente, no es así: esa preposición, vaya donde vaya, no se refiere jamás al relativo, sino al antecedente, cuya función con el verbo subordinado marca.

No se comprende por qué ha de interpretarse el que como un nombre (o pronombre, que, para este caso, lo mismo da), simplemente para justificar la aparición del artículo o de la preposición, en aras de la hipótesis quimérica y apriorística de que estos signos sólo pueden aparecer físicamente delante de los nombres, y no tras ellos. ¿Por qué no aceptar los hechos como son, sin inventar imaginarias naturalezas nominales, y describir así el fenómeno como realmente es, es decir, reconociendo el hecho de que en las llamadas oraciones de relativo, tanto las preposiciones correspondientes a la segunda función del antecedente, como el artículo que pueda corresponderle al mismo, también en la segunda función, se colocan delante del relativo en la disposición material o distribucional de los elementos sintácticos, pero no en su estructura semántica? Porque, vistas así las cosas, desaparecen una serie de seudoproblemas y de alambicadas explicaciones de hechos de naturaleza mucho más sencilla.

$Y$, por otra parte, no hay más remedio que reconocer que la explicación que propongo es la única que coincide con la interpretación idiomática natural de estos hechos. Como dije más arriba, desglosar una construcción como «perro que ladra no muerde» en dos estructuras diferentes con un elemento común y repetido es contrario a la realidad, en la que no se siente tal duplicación de unidades, sino la incidencia simultánea de dos funciones en un mismo elemento, es decir, en un elemento que no se ve como desdoblado, sino como bifuncional. Y así, aunque desde un punto de vista lógico-genético puede considerarse que «perro que ladra no muerde» envuelve dos juicios sobre la realidad, la verdad es que desde el punto de vista del significado idiomático, que es el único que puede interesarnos ahora, lo que sucede es que la duplicidad de función significada por el relativo es el único factor que consigue esa absoluta cohesión

"La construcción de ignorar con objeto directo de persona indeterminada es insólita fuera de estos casos en que la segunda función hace más normal la expresión. Usado con a y complemento de persona, toma el sentido de 'hacer caso omiso', seguramente un anglicismo semántico. 
que ya Bello atribuía al relativo, en oposición a otros determinantes, que, como este, sólo logran un enlace flojo entre cláusulas: es la diferencia entre los signos relativos, capaces de significar dos funciones simultáneas, y los que sólo pueden referirse a una sola, aunque se usen también anafóricamente.

***;

Aclarada, pues, la condición natural de los determinantes o pronombres, que no consiste ni en sustituir ni en repetir nada, sino en señalar ciertas posiciones, suposiciones o extensiones, en el universo del discurso (este «pone» una sustancia; $e l$, la «supone»; mucho, la «extiende») o en el del texto (que, quien, donde), puedo volver con más seguridad a la cuestión que ponía al principio como ejemplo típico de las interpretaciones incorrectas a que pueden conducir unos presupuestos gramaticales mal planteados. En efecto: una vez supuesta la hipotética naturaleza, a la vez sustantiva y reproductora, del relativo, la aparición de nuevos pronombres anafóricos referidos al antecedente lleva automáticamente al cuestionamiento de su función, tanto porque se considere que su papel se vuelve redundante sin más, como porque se piense que abandona su condición «pronominal», es decir, reproductora, para transformarse en un puro nexo o elemento de valor únicamente relacionante (como si fuera algo más que eso en las oraciones adjetivas de toda clase $)^{5}$. Y de esta manera, lo que sucede en las oraciones de relativo que incluyen pronombres alusivos al antecedente acaba tomándose por una simple anomalía consistente en la desnaturalización del relativo, cuando, por el contrario, son, justamente estas construcciones las que permiten ver mejor la inexistencia de límites entre unos imaginarios que diferentes: es tan grande la fuerza de la tradición que atribuye al relativo una naturaleza nominal y reproductora, que ni aun el hecho de tratarse de un fenómeno común, tanto en la lengua literaria, como en la hablada y tanto en el español de hoy, como en el de todos los tiempos, ha impedido que los gramáticos hablen de «anomalía» ${ }^{6}$, lo que no deja de tener gracia, tratándose de un fenómeno absolutamente normal.

No hay, pues, despronominalización del relativo en construcciones como «es el señor al que le dieron el premio» o «tengo un hermano que lo respeto como si fuera mi padre», más que si se piensa o se cree que esos que son,

${ }^{5}$ Lope Blanch dice textualmente que «el relativo se "despronominaliza" (...) por cuanto que, mediante este desdoblamiento (...), conserva únicamente su función nexual, en tanto que la pronominal -es decir, su relación anafórica con el antecedente-queda a cargo del otro morfema...» Cfr. «Despronominalización de los relativos», en Estudios de lingüística española, Universidad Nacional Autónoma de México, México, 1986, pp. 119-136.

6 «Llama poderosamente la atención la inseguridad y aun la torpeza con que, en todas las modalidades del habla, se emplean los pronombres relativos. Tanto en la lengua hablada —popular o culta- cuanto en la escrita — común o artística-, es relativamente elevado el número de irregularidades que pueden descubrirse en el uso de los nexos pronominales relativos». Vid. J. M. Lope Blanch, op. cit., pp. 119. Subrayamos nosotros. 
respectivamente, el señor y un hermano. $\mathrm{Si}$, por el contrario, se interpreta el relativo como se ha dicho más arriba, nos volvemos a encontrar con que lo que hace esa partícula en estos casos es mostrar la doble función del antecedente en relación con los verbos de dos cláusulas distintas, por lo que, desde este punto de vista, no existe la menor diferencia entre estos ejemplos y sus variantes sin esos pronombres anafóricos: «es el señor al que dieron el premio»o «tengo un hermano que respeto como si fuera mi padre».

El verdadero problema de estas oraciones adjetivas con pronombres (e incluso con nombres) referidos al antecedente no consiste en que se «vacíe» el relativo, que no se puede vaciar porque nunca se llena con nada que no sea su propio y genuino contenido, sino en que la condición bifuncional del antecedente se ve afectada por la aparición de elementos que sí representan su segunda función y que, en consecuencia, debilitan la unicidad que es propia de esta clase de cláusulas y favorecen su interpretación única como explicativas, en ciertas condiciones que veremos luego. Pero tal debilitamiento de la condición bifuncional del antecedente no es exclusivo de estas construcciones, sino una peculiaridad que ellas tienen en común con todas las adjetivas explicativas, en las que, por su condición de incisos o de cláusulas incidentales o parentéticas, la «segunda» función deja de existir realmente: en la cláusula adjetiva explicativa lo que sucede en verdad es que el antecedente está sobrentendido, al revés que en la especificativa, donde el antecedente es miembro a la vez de la cláusula incluyente y de la incluida. Cuando se dice, por ejemplo, «los niños, que estaban muy cansados, se fueron a la cama», que estaban muy cansados se entiende como una segunda oración parentética de sujeto sobrentendido, del tipo «estaban muy cansados», «como estaban muy cansados», «pues estaban muy cansados», etc., y no como un apéndice de niños, es decir, como un verdadero constituyente semántico de los niños se fueron a la cama.

Pero sin embargo, no todas las cláusulas adjetivas con pronombre anafórico de este tipo son necesariamente explicativas. Una buena parte de ellas pueden ser especificativas cuando la «segunda» función del antecedente es la de objeto directo, indirecto, e, incluso, término de preposición. El requisito exigido es, especialmente en la función de objeto directo, la «novedad» de la mención anafórica, esto es, que el grado de determinación de ésta no coincida enteramente con el que posea el antecedente. Se dice así, especificativamente, «es un libro que me lo recomendó el profesor», «tenía algunas novelas que no las habíamos visto nunca», «poseía esa mala educación que no la vemos nunca en la gente del pueblo», etc.: es muy probable que, en todos estos casos, si los antecedentes hubieran llevado artículo, no se habría repetido su «variante verbal» en las cláusulas adjetivas, pues no decimos de manera natural «es el libro que me lo recomendó el profesor», sino «que me recomendó», ni «tenía las novelas que no las habíamos visto nunca», sino «que no habíamos visto nunca», ni «poseía la mala educación que no la vemos nunca en la gente del pueblo», sino «que no 
vemos nunca», etc. E igual sucede con los casos en que la segunda función es preposicional, aunque los ejemplos pertenecen por lo general todos ellos al lenguaje coloquial y descuidado, como los que cita Lope Blanch (op. cit): «se trata de una idea que ayer daba vueltas sobre ella», «y unos niños que me acuerdo muy bien de ellos». No creo que se hubiera llegado a decir, ni siquiera descuidadamente, «la idea que ayer daba vueltas sobre ella», ni «los niños que me acuerdo muy bien de ellos», salvo que se hubieran empleado explicativa y no especificativamente. Con todo, como se verá luego, cuando el pronombre anafórico es objeto indirecto, no constituye siempre un obstáculo la coincidencia con el grado de determinación del antecedente, como consecuencia de las diferentes funciones semánticas que, respectivamente, corresponden a $l o$ y a le.

$* * *$

La única peculiaridad relevante que presentan, pues, las oraciones de relativo con pronombre anafórico referido al antecedente es la del debilitamiento que puedé sufrir, en mayor o menor medida, la condición de elemento bifuncional que posee ese antecedente de las adjetivas especificativas, aunque, como se ha visto, no es en absoluto regular y homogéneo tal debilitamiento de la relación. $\mathrm{Y}$, además, la «quiebra» de la bifuncionalidad no constituye nunca una anomalía gramatical, salvo para los que sólo consideran como normal lo que se ajusta a esa hipótesis quimérica, aunque común, que mezcla un cierto logicismo «doméstico» con criterios propios de la gramática latina.

La aparición de pronombres anafóricos (e, incluso, de nombres) en las cláusulas adjetivas no produce otro efecto real que el de poner en peligro la bifuncionalidad del antecedente, cuya «segunda» función tiene entonces un signo específico y diferenciado que la marca separadamente. Y ya se ha visto, además, que esta separación explícita de las funciones tiende a transformar la adjetiva en puramente explicativa, lo que en el fondo significa, como también se ha visto, un cambio real de estructura sintáctica, dado que las adjetivas explicativas no se definen por la presencia de un elemento bifuncional, sino por el hecho de que el antecedente se separa de la cláusula subordinada, en la que sólo «se repite» como elemento sobrentendido: de su condición de término único con doble función, sobre el que concurren dos verbos, pasa a la de dos términos separados, con funciones diferenciadas en cada una de las cláusulas.

Ha sido en realidad el análisis «lógico» (por llamarlo de alguna manera) el que ha establecido dos tipos sintácticos de oraciones adjetivas, especificativas unas y explicativas otras. Sin embargo, y pese a las apariencias, tales tipos no tienen la misma estructura sintáctica, más que si se consideran los hechos desde la perspectiva del relativo considerado como un sustituto reproductor. Por el contrario, si nos atenemos a los datos reales, lo que parece suceder en la llamada especificativa se reduce al hecho de que el antecedente presenta una función doble pero simultánea con dos verbos distintos, actuando como la 
bisagra que los une, mientras que en la llamada explicativa lo que ocurre es que el antecedente (que nunca deja de serlo) abandona su condición de miembro simultáneo de dos cláusulas, para pasar a ser y a sentirse como un constituyente exclusivo de la subordinante, sobrentendido luego en la subordinada.

Esta es una cuestión que se ve muy bien cuando el antecedente es el artículo: en «los que estaban cansados se fueron a la cama», los contrae una relación simultánea con estaban y con se fueron, relación que se disocia al hacerse explicativa la proposición adjetiva: «ellos, que estaban cansados, se fueron a la cama». Ahora ya no pivotan dos verbos sobre ellos, sino sólo se fueron: que sigue estableciendo una correlación, pero no ya entre los dos predicados del mismo sujeto, sino entre una cláusula o un elemento de ella y otra cláusula incidental, con la estructura semántica 'ellos se fueron a la cama: ellos estaban cansados': de un sujeto común para los dos verbos, se pasa a uno para cada uno, en la interpretación semántica de la secuencia. En la llamada especificativa, el antecedente desempeña una doble función; en la explicativa, por el contrario, desempeña una función «expresa» en la principal y una función «tácita», en la subordinada: ahora la relación es más entre dos oraciones diferentes, relacionadas por el relativo, que entre dos verbos que el relativo conecta con un nombre o pronombre único.

De todas formas, el debilitamiento del lazo a causa de la referencia anafórica no llega siempre a romper la posibilidad de cláusulas especificativas, como se ha visto más arriba que sucede con frecuencia cuando la segunda función del antecedente es la de objeto directo o indirecto, e, incluso, término preposicional, si bien esta cuestión se relaciona al menos en ciertos casos, con el hecho de que al antecedente corresponda diferente tipo de determinación en cada una de sus funciones. Basta con recordar nuestros ejemplos, en los que la determinación de la primera función era diferente de la determinación de la segunda: en «es un libro que me lo recomendó el profesor», un representa un tipo de determinación diferente de la de $l o$ : si el grado de determinación fuera el mismo, como sucedería si empleásemos la variante «adjetiva» el para la primera función y la variante posverbal «sustantiva» $l o$, para la segunda, la secuencia sería imposible, o, al menos, incorrecta ( «*es el libro que me lo recomendó el profesor»), salvo que, como también se ha dicho, la cláusula adjetiva fuese explicativa, es decir, de estructura gramatical y semántica diferente: «es el libro, que me lo recomendó el profesor», expresión ya difícilmente interpretable como estrictamente adjetiva, pues la relación que significa que se establece ahora más entre cláusula y cláusula que entre un antecedente nominal y su adjetivo.

$$
* * *
$$

Todo lo dicho hasta aquí acerca de la naturaleza semántica y gramatical de que y de las cláusulas adjetivas con o sin referente anafórico de la segunda función del antecedente me lleva no sólo a rechazar por inexacta la idea de 
despronominalización, sino también esa falsa noción, que lleva implícita, del pronombre como un signo vacío y sustitutivo de significados ajenos. Los pronombres o determinantes sólo tienen contenido deíctico y ni sustituyen ni se «rellenan» con el significado de otras palabras, sino que, todo lo más, sitúan a esas posibles palabras de acuerdo con sus propios significados, sea de forma directa («iqué libro has escrito!»), sea anafóricamente («jel libro que has escrito!»). Sólo creyendo que existe un que sustitutivo y sustantivo, se puede montar una explicación tan fantástica como la de la despronominalización, que es un fenómeno íntimamente relacionado con la «omisión» de las preposiciones ante el relativo no sólo en el lenguaje coloquial, donde la falta de la preposición es frecuentísima, sino también en el lenguaje cuidado y en el literario. Se trata igualmente de un hecho «normal», por lo que hablar de anomalías es volver a confundir lo que es el relativo realmente, con la creencia en su metafísico carácter sustantivo. La falta de la preposición ante el relativo responde a la vacilación que se deriva tanto de la bifuncionalidad del antecedente como del hecho de no sentirse idiomáticamente el que como el verdadero término de la rección, es decir, como sustantivo. De la misma manera que se dice $-\mathrm{y}$ no creo que incorrectamente-- «la noche que llegué» (y no en lugar de «la noche en que llegué», como creen los que se afanan en ver una naturaleza nominal en la partícula relativa), se dice, especialmente en la lengua «descuidada», esto es, no condicionada por fantasías gramaticales, «me hablas de un asunto que yo no puedo opinar sobre él», que no es más que una versión «superficial» diferente de una oración cuya forma «cuidada» ( «me hablas de un asunto sobre el que yo no puedo opinar») es sólo una variante de una única estructura semánticosintáctica básica. En un caso donde no hubiera habido dos regímenes preposicionales diferentes para cada una de las funciones del antecedente podría haber sucedido también que esa preposición, que se ha ido al final con un pronombre tónico, hubiera ido a parar al antecedente: «ya sabes sobre el asunto que tu hermano se ha metido a opinar», frente a «ya sabes el asunto sobre el que tu hermano se ha metido a opinar», e, incluso, frente al desaliñadísmo, pero no imposible, «ya sabes el asunto que se ha metido tu hermano a opinar sobre él».

Hablar para unos casos de despronominalización y para otros de «gramaticalización» del que ${ }^{7}$ es incurrir siempre en el mismo error que confunde la función determinante con una propiedad sustitutiva de que carece cualquier signo de cualquier lengua. Por eso digo que despronominalización y gramaticalización son términos que responden al mismo tipo de confusión. No se «gramaticaliza» el que que aparece sin la preposición que debiera

\footnotetext{
${ }^{7}$ Juan Alcina y José Manuel Blecua (cfr. Gramática española, Barcelona, 1975, párr. 8.1 2.2.), además de aclarar, como hacen todos, que que desempeña «función sintáctica en relación con el verbo de la proposición» subordinada, añaden que «la ausencia de preposición en casos en que debiera llevarla no es infrecuente y marca el paso a la gramaticalización del que». Es curioso como el prejuicio sobre el carácter nominal de este que lleva a hablar de un proceso de gramaticalización cuya duración debe de ser eterna, si se tiene en cuenta, por un lado, que la partícula sólo es y ha sido gramatical, y, por otro, que no se ha sentido nunca como elemento de significado nominal.
} 
corresponderle a la segunda función del antecedente, en primer lugar porque sólo puede ser un signo gramatical y no léxico, y en segundo lugar porque tal cosa no significa que cambie desde una hipotética naturaleza nominal a otra conjuntiva no menos hipotética. Habría esa gramaticalización de que hablan algunos si se tratara de un verdadero nombre que perdiese su significado para transformarse en un mero instrumento sintáctico: pero eso no sucede jamás: que, en cualquiera de sus usos, es siempre un instrumento gramatical y la supuesta pérdida de la preposición es la mejor prueba de que no se le siente como nombre, particularmente en el habla espontánea, al revés de lo que sucede en el lenguaje latinizado por la tradición renacentista, deseosa siempre de restaurar las perdidas distinciones del relativo qui.

\section{$* * *$}

Hablar, en fin, de anomalías es, como se ha ido viendo, un tanto impropio, pues, en los supuestos contemplados, no sufre el relativo ningún cambio en su contenido ni en su función. Lo que sí cabe hacer es hablar de diversos tipos de cláusulas adjetivas, cada uno de los cuales, sujeto a las reglas que lo rigen, sí es susceptible de presentar ciertas anomalías específicas. Pero veamos antes que nada cuáles son los tipos de oraciones adjetivas existentes desde el punto de vista de que aquí estamos tratando:

\section{Especificativas:}

1.1. El antecedente es bifuncional y no aparece ningún pronomore anafórico referido a él;

1.2. El antecedente es bifuncional, aunque aparece un pronombre anafórico referido a él;

2. Explicativas (el antecedente no puede ser bifuncional):

2.1. Sin pronombre anafórico referido al antecedente;

2.2. Con pronombre anafórico referido al antecedente.

Ya se ha dicho más arriba que no se puede hablar de una manera realista de oraciones adjetivas especificativas y explicativas como de dos clases de una estructura sintáctica o sintáctico-semántica única, porque lo que separa a las unas de las otras no es otra cosa que el diferente tipo de relación que mantiene el antecedente con las cláusulas «subordinante» y «subordinada». Se ha visto cómo, aparte de toda consideración lógica impertinente, en la llamada subordinación adjetiva especificativa lo que sucede realmente es que el antecedente no se desdobla a pesar de desempeñar dos funciones simultáneas en relación con dos verbos distintos, ni a pesar de que la diversidad de funciones pueda acarrear la presencia de marcas diferentes que se sitúan normalmente delante del relativo, aunque sólo se refieran al antecedente, sin que sea insólito 
que su distribución vacile en ciertas circunstancias entre una posición y la otra.

Y es precisamente esta actuación semántica del antecedente como centro de dos funciones simultáneas lo que llamamos adjetivación especificativa y lo que hacía decir a Bello, comparando «las estrellas son otros tantos soles; éstos brillan con luz propia» y «las estrellas son otros tantos soles que brillan con luz propia», aquello de que «que tiene el mismo significado que éstos; es un verdadero demostrativo; pero se diferencia de los demostrativos comunes en que la lengua lo emplea con el especial objeto de ligar una proposición con otra» (Gramática, 303). Efectivamente: que y éstos son demostrativos, es decir, determinantes, si bien de distinto significado particular: con éstos el «enlace es flojo y débil» ( $\mathrm{Ib}$.), al revés de lo que sucede con que. Bello veía como solidez del enlace lo que no es únicamente un enlace entre dos proposiciones distintas, sino, más propiamente, un enlace entre un nombre y dos predicados diferentes y simultáneos. Estos no es verdaderamente una partícula relativa y en eso se diferencia de que: con éstos no puede haber más que un sujeto sobrentendido, al que el demostrativo se aplica, mientras que, con que, soles puede ser, al mismo tiempo, predicado nominal del sujeto las estrellas y sujeto de brillan, sin que haya que sobrentender, para este último, el contenido 'soles', que ya se halla expreso ante el relativo. Es esencial entender que en las cláusulas de relativo especificativas, ni está el antecedente reproducido en la subordinada, ní sobrentendido en ella, sino que es, por el contrario, un constituyente natural y directo de ella.

Pero esta duplicidad funcional se rompe, como se ha visto ya, en las llamadas explicativas, en las que sí notamos la flojedad del enlace, que Bello atribuía a éstos: en «las estrellas, que brillan con luz propia, son otros tantos soles», la flojedad del enlace es la misma que hay en «son otros tantos soles las estrellas: (éstas) brillan con luz propia»: en un caso y en el otro, el sujeto de brillan es estrellas sobrentendido, con independencia de que en un caso esté determinado por que y en el otro por éstas: la simultaneidad funcional ha desaparecido y la subordinada no pende directamente del antecente, sino de su repetición semántica, como elemento sobrentendido.

Esta es la razón por la que asignamos una interpretación gramatical diferente a las adjetivas explicativas: al revés de lo que sucede en las especificativas, el antecedente no es un constituyente directo suyo: la única relación que se establece entre «principal» «subordinada» consiste en el hecho extragramatical de que en la segunda se contiene una referencia contextual al antecedente. Y es esta diferencia, en lo que se refiere a la función del antecedente, lo que acerca el caso de las adjetivas explicativas al de las adjetivas que contienen una referencia anafórica a lo que he llamado aquí «segunda función» del antecedente. La aparición de ese referente anafórico, generalmente pronominal, separa la primera función del antecedente (la que contrae con el verbo de la principal) de la segunda, es decir, de la que mantiene con el verbo subordinado, y esta 
«ruptura» funcional, este cambio en el funcionamiento sintáctico del antecedente, provoca la estructura explicativa de la cláusula dependiente, salvo, como ya se ha visto, que el representante de la segunda función agregue información semántica nueva, diferente de la contenida en el antecedente, o que sea objeto indirecto del verbo subordinado.

Por todo ello, he incluido entre las oraciones de relativo propiamente dichas o especificativas no sólo las «normales», sino también todas aquellas otras que presentan referente anafórico del antecedente bajo una situación de determinación diferente de la que éste posee en su «primera» función, y, sin este requisito, cuando el referente anafórico es objeto indirecto. En «compró un libro que se $l o$ había recomendado su profesor», el referente $l o$, de la segunda función del antecedente (la que contrae con había recomendado), reproduce un tipo de determinación totalmente diferente de la que representa un en la primera función de ese mismo antecedente (la que contrae con compró): lo no reproduce de ninguna manera un libro, sino que introduce el nuevo contenido semántico que habría correspondido a el libro, ya que es simplemente una variante combinatoria de $e l^{8}$. No hay, pues, al menos, una reproducción «absoluta» del antecedente, sino una referencia a él, bajo otra forma gramatical y semántica, con lo que se mantiene su unicidad funcional bien separada de los signos alusivos a una y otra función. No es igual, pero sí muy frecuente, el caso del referente objeto indirecto, con igual o diferente grado de determinación que el antecedente: «allí estaba el escritor que le dieron el premio». De éste hablaremos luego.

Estas construcciones no sólo son abundantes, particularmente cuando la segunda función es la de objeto directo, indirecto o término de preposición, sino que en ocasiones parecen preferibles a las pretendidamente «normales». En la segunda función como objeto directo se diría, por ejemplo, sin dificultad «nos encontramos con unas viviendas que las habían ocupado los inmigrantes», «buscábamos unos libros que ya los había leído todo el mundo», «eran unas casas que no las quería nadie», "no eran unos cuadros que los vendieran en cualquier parte». No sólo la normalidad de expresiones como éstas, sino, incluso, su mayor probabilidad de aparición, favorecida tanto por el diferente grado de determinación de las funciones simultáneas de los antecedentes, como por la posible ambigüedad de la subordinada, parecen también pruebas claras de que no se puede hablar de anomalías, ni de cambio de función del relativo, ni de nada semejante. Al contrario, convendría determinar las circunstancias en que no sólo son comunes estas construcciones, sino también acaso semánticamente necesarias, sin olvidar al mismo tiempo las circunstancias de lo que podríamos llamar su uso incorrecto o, al menos, torpe. En todo caso, el carácter explicativo depende de lo que hemos dicho o de la determinación inicial absoluta del

${ }^{*}$ Hace más de siglo y medio, Bello hizo ver la identidad entre el artículo y el pronombre personal de tercera persona, como variantes de expresión de un mismo signo, para funciones o distribuciones diferentes. Cfr. «La cuestión del artículo en español», ya citado. 
antecedente, como sucede en este ejemplo citado por Lope Blanch (op. cit., p. 122): «hace caso a su papá, que lo admira mucho». Hubiera sido especificativa, por ello, sin dificultad, con sólo cambiar el grado de determinación de la primera función del antecedente: «había dos profesoras que las admirábamos mucho», «tenía dos amigos que los buscaba la policía».

Con todo, sin embargo, estas construcciones adjetivas de objeto directo anafórico no son más que variantes combinatorias, es decir, distribucionales, concurrentes con aquellas otras que presentan el artículo ante el relativo cuando las circunstancias semánticas piden la preposición $a$ : «hace caso a su papá, al que admira mucho», «tenía dos amigos a los que buscaba la policía». Lo único notable, en estos casos, es que, si no hay preposición, esta variante última es imposible: sólo se dice «buscábamos unos libros que ya los había leído todo el mundo» (o «que ya había leído todo el mundo»), pero no «*buscábamos unos libros los que ya había leído todo el mundo», porque a el que y sus variantes le pasa lo mismo que a el cual y las suyas, con la diferencia de que el cual no aparece normalmente sin preposición y el que sí puede hacerlo cuando el artículo se usa como término primario, con o sin referencia anafórica. Lo, la, los, las, referidos al antecedente en las cláusulas adjetivas, no son, pues, más que variantes, también anafóricas, de $e l, l a, l o s, l a s$, precedidos de la preposición $a$, cuando deban situarse ante el relativo y no tras él.

Cuando la segunda función del antecedente es la de objeto indirecto, es más frecuente la aparición de un pronombre anafórico, tremendamente normal en la lengua coloquial y nada extraño en la escrita. Tales cláusulas son por lo general especificativas y representan una alternancia igual y del mismo valor que la que se observa en el caso de los objetos directos que acabamos de ver (esto es, los que requieren la preposición $a$ delante del determinante, cuando éste ha de preceder al relativo): "hay gente que le gusta vivir así», "es el señor que le dieron el premio», etc. Debe observarse, además, que no se usa la presunta forma normal «hay gente a la que gusta vivir así», sin esa imaginaria despronominalización del que. Se dice tanto explicativamente «te presento a mi hermano, que ya le concedieron la jubilación», como especificativamente «ese es el escritor que le dieron el premio». La construcción supuestamente «correcta» antepone el artículo, precedido de la preposición, al relativo, pero suele mantener la variante pronominal del artículo dentro de la cláusula adjetiva: «te presento a mi hermano, al que ya (le) concedieron la jubilación», «ese es el escritor al que (le) dieron el premio», «hay gente a la que (le) gusta vivir». Es evidente que en estos casos, lo normal es la famosa anomalía y que nadie diría, por ejemplo, «hay gente a la que gusta vivir», suprimiendo ese le al que, con excesiva ligereza, se le atribuye la despronominalización del relativo.

Pero, como ya se ha dicho y al contrario de lo que sucede con los objetos directos, ahora no parece haber conflicto entre el grado de determinación que corresponde a la primera función del antecedente y el que corresponde a la 
segunda, que puede ser el mismo, como se ve en ejemplos del tipo «ese es el escritor que le dieron el premio», sin que por ello la cláusula tome valor explicativo. Mientras que empleamos una y no la en «encontré a una joven que ya me la habían presentado antes», podemos repetir el determinante, como objeto indirecto, en «encontré a la joven (o «a una joven») que le (o «a la que le») habían prestado mi libro».

La causa de esta diversidad de trato parece estar, aunque quizá no exclusivamente, en el diferente valor complementario de lo y sus variantes frente al de le y las suyas. Mientras que lo, que funciona como complemento «primario», forma una sola unidad semántica con el verbo del que depende, le, que es un complemento «secundario» o mediato, se distancia de ese contenido verbal, constituyendo siempre como una referencia externa a él ${ }^{9}$. Y como quiera que la clave de las construcciones adjetivas o de relativo consiste, como se ha dicho, en que el antecedente contrae simultáneamente función con el verbo de la principal y con el de la subordinada, deben esperarse resultados muy diferentes según se emplee un complemento como lo, que integra verbo subordinado y antecedente, o un complemento como le, cuyo carácter externo no produce ningún tipo de integración semántica entre verbo y complemento. De esta manera, la anáfora con lo se siente como una reproducción «total» (es decir, como una duplicación) del antecedente y de su grado de determinación en la subordinada, a la que transforma por fuerza en explicativa, mientras que en la anáfora con le se percibe sólo como una alusión redundante al antecedente, sin que por ello haya de quebrarse la unidad de la especificativa. Frente al lo, que sólo puede ser pleonástico en las explicativas, está ese le que se usa redundantemente de manera natural, tanto en explicativas como en especificativas. $Y$ así se dice, en estilo coloquial, «allí estaba el escritor que le dieron el premio», pero no «*allí estaba $e l$ escritor que lo premiaron», sin que influya la circunstancia de la posible alternancia con $a$ y artículo ante el relativo, pues en ambos casos se diría al que («el escritor al que dieron el premio» y «el escritor al que premiaron»). El carácter «mediato» de le permite recoger la referencia y repetirla como algo que está en segundo plano, y así puede resultar posible «era la joven que le habían buscado una silla en el salón», pero no «*era la joven que la habían buscado en el salón», especificativamente: le señala un segundo plano en la complementación verbal, por lo que no se siente como parte del contenido del verbo, al contrario de lo que sucede con $l a$, que señala el primer plano de la complementación, por lo que se siente particularmente como parte de ese contenido verbal: le se limita a «aludir» al antecedente sin implicarlo en la significación verbal; la, en cambio, lo repite y lo implica en ella, lo que parece entrar en conflicto con su unicidad funcional (su bifuncionalidad).

${ }^{9}$ En Introducción a la semántica española (Arco/ Libros, S. A., Madrid, 1988), he tratado acerca del diverso tipo de integración de estos complementos, con independencia siempre de su posible identificación con las nociones tradicionales de complemento directo e indirecto (Cfr. Cap. XIX y XX). 
$\mathrm{O}$, visto de otra manera, podemos decir que la diferencia entre «era un libro que lo habíamos leído juntos» y «era el libro, que lo habíamos leído juntos» está en que, en el primer caso, lo completa la información introducida por un, que es un determinante de valor diferente, y se siente, en consecuencia, como parte de una misma unidad de significado, mientras que, en el segundo, lo repite el el del antecedente, rompiendo la unidad estructural, esto es, desglosándola en dos enunciados semántica y sintácticamente diversos. La segunda cláusula adjetiva sólo puede ser explicativa porque el determinante repetido se disocia de «era $e l$ libro» y no se integra más que con el otro verbo, habiamos leído, en tanto que en «era un libro que lo habíamos leído juntos», nos encontramos con que es libro, precisamente, el elemento que integra en forma simultánea a los dos verbos, si bien en dos grados de determinación sucesivos y diferentes $(u n \rightarrow e l)$.

De esta manera, pues, vemos cómo y de qué manera pueden mantener su carácter de especificativas ciertas cláusulas adjetivas que contienen alguna referencia anafórica al antecedente. $Y$ acaso pueda el uso formularse en la forma de unas pocas reglas como éstas:

1. Lo anafórico y sus variantes aparecen como objetos directos de adjetivas especificativas si el antecedente no tiene el grado de determinación propio del artículo o cualquier otro determinante que posea el contenido de la identificación, como los demostrativos o los posesivos. No parece, por ello, congruente ni «coloquialmente normal» una expresión como «vi la película que me la recomendó el profesor». Ejemplos de este objeto directo anafórico, referidos a un antecedente con un grado de determinación diferente, abundan en los mejores escritores. Transcribo algunos del Quijote, citados por Lope Blanch y tomados de un recuento hecho por Henry S. Gehman: «otra desgracia, que Sancho no la tuvo por la peor», «cosa que la juzgó a milagro», «dos prendas que las estimo».

1.1. En muchos casos puede suceder que alguna ambigüedad u oscuridad del sentido favorezca la aparición del complemento directo anafórico: parece preferible, por ejemplo, «era un hombre que no lo conocía nadie» a la supuestamente más correcta, pero acaso confusa, «era un hombre que no conocía nadie», fonéticamente próxima de «que no conocía a nadie».

2. Si el antecedente lleva artículo, demostrativo o posesivo, la cláusula adjetiva es normalmente explicativa. Se habría podido decir, en efecto, «vi la película, que me la recomendó el profesor». En el recuento citado en 1. no aparece ningún ejemplo de este tipo en oración especificativa, como es natural.

3. Le, les anafóricos son extraordinariamente frecuentes como objetos indirectos en cláusulas adjetivas especificativas, aunque el antecedente vaya determinado por el artículo, el demostrativo o el posesivo. Así, junto con la forma cuidada, no extrañaría «ahí está el jardín que le pusieron la valla». Hay ejemplos de Cervantes en el recuento mencionado en 1. que ni siquiera podrían usarse sin incurrir en la supuesta anomalía: «algunas mujeres que se les antoja comer tierra», «caballero aventurero que mala ventura le dé Dios». Lope Blanch estima que 
«la duplicación de pronombres es verdaderamente notable en el Quijote» (op. cit., nota 46), y uno se pregunta cómo habrían podido entenderse los dos ejemplos citados, sin la «duplicación», aun considerándolas como construcciones absolutamente «correctas», pero un tanto desaliñadas: «algunas mujeres a las que se antoja comer tierra», «caballero aventurero al que mala ventura dé Dios».

4. Le, les anafóricos concurren con frecuencia con el artículo precedido de $a$, ante el relativo, y en ciertas ocasiones, como sucede con verbos del tipo gustar, agradar, su presencia resulta obligatoria, por lo que no puede considerarse redundante más que semánticamente (así «hay gente a la que le gusta vivir», con un le obligatorio, frente a «era el escritor al que (le) habían dado el premio»).

5. Con pronombre anafórico sujeto son raras las construcciones especificativas pero parecen seguir la misma regla, si bien el pronombre suele tomar un valor de reiteración enfática y expresiva, y acompañarse de algún determinante con la misma intención: «hay mujeres que acaban ellas mismas con quienes las desean», «tenía un coche que estaba todo él para el desguace», «era una mujer que todavía estaba ella de buen ver». Resulta raro como especificativo, pero no imposible, el ejemplo que recoge Lope Blanch (op. cit. p. 126): «el otro día un amigo nuestro que él es notario nos dijo...». En todo caso, el grado de normalidad varía mucho si comparamos las cláusulas de pronombre reiterativo, con las demás, en las que el pronombre sujeto facilita la rotura definitiva de la bifuncionalidad del antecedente.

He querido limitarme al determinante relativo que, a pesar de que el fenómeno que aquí comento se da por igual con los demás relativos, como puede verse, con abundancia de ejemplos, en el notable y pormenorizado estudio de Lope Blanch que motivó las presentes reflexiones. Y la razón de esta limitación no es otra que la identidad del asunto: cada uno con sus especificidades semánticas, quien, el cual, cuyo y donde, encabezan o pueden encabezar cláusulas adjetivas en las que se pierde la bifuncionalidad del antecedente, bien por ser explicativas sin más, bien por causa de la presencia de pronombres anafóricos referidos a ese antecedente. Con todo, creo que pueden añadirse algunas observaciones sobre las peculiaridades semánticas de esos otros relativos y de sus diferencias mutuas.

Respecto de esos relativos, lo primero que hay que decir es que tampoco son sustitutos de nombres o equivalentes de éstos, como pueden sugerir las concordancias en número, de quien, o en género y número, de el cual y de cuyo. Como construcciones, no hay diferencia entre «eran unos libros en los que aprendió cuanto sabía» y «eran unos libros en los cuales aprendió lo que sabía». En el español de hoy, cual funciona como relativo precedido del artículo e, introduciendo cláusulas especificativas, sólo con preposición. Pero no debe nadie confundirse con el hecho de que este relativo tome el género y el número 
de su antecedente, porque es ésta cuestión absolutamente «superficial», pues el género y el número sólo expresan su verdadero contenido con los nombres, pero nunca con los adjetivos ni con los determinantes, con los que estos morfernas sólo significan una cierta vinculación sintáctica absolutamente arbitraria, y así, mientras que el cual y quien concuerdan con su antecedente, cuyo lo hace con un nombre de la subordinada, al que determina junto con su antecedente, con el que no lo une marca morfológica de ninguna clase. Estas concordancias son sólo marcas físicas de ciertas relaciones distribucionales; pero no de la existencia de contenidos nominales, como suele suponerse en el caso de quien y de el cual, o adjetivos, como en el caso de cuyo.

En «eran unos libros en los cuales aprendió lo que sabía», ni el número, ni el género, expresados por el artículo obligatorio, significan que cuales sea un sustantivo o un equivalente suyo, sino sólo la identificación física del antecedente, por lo que la lengua escrita prefiere este relativo para los casos en que el antecedente se encuentra lejos o en que su identificación resulta problemática (en la lengua hablada, el uso de el cual es normalmente afectado). Tanto el cual como quien están absolutamente vacíos de contenido nominal y son relativos $\tan$ «puros» como que, aunque con limitaciones semánticas y distribucionales mayores: el cual no puede formar especificativas más que precedido de preposición, y quien sólo determina antecedente de persona y ha de construirse necesariamente con preposición si ese antecedente está expreso. Sin antecedente expreso ( $y$ sin preposición) se refiere siempre al sujeto personal del verbo subordinado. $\mathrm{Y}$ en cuanto a cuyo, restringido al uso culto, sucede también lo mismo, con la peculiaridad de que este determinante es, en cierto sentido, «doble», pues funciona como cualquier otro relativo con relación al antecedente y como posesivo de tercera persona con relación a un nombre de la cláusula subordinada. Decir, como se hace, que cuyo es un adjetivo no es más que confundir categoría con función.

Sentado, pues, el principio de que estos elementos no son sustitutos nominales, como ya hemos visto que tampoco lo es que, debemos ahora constreñirnos a los frecuentes casos de aparentes despronominalizaciones y desdoblamientos que observan los gramáticos cuando la bifuncionalidad del antecedente se rompe por alguna razón.

Para empezar, ha de tenerse en cuenta que quien y el cual, construidos con antecedente expreso, han de ser especificativos y exigir siempre preposición para la segunda función, aunque quien puede también llevarla, construido con antecedente sobrentendido («se comportó como a quien correspondía» ${ }^{10}$. Estas restricciones son paralelas de la menor frecuencia de pronombres anafóricos en

\footnotetext{
${ }^{10}$ No es correcto el uso explicativo sin preposición de quien y, por tanto, no deben decirse cosas como «Fulano, quien había hecho las primeras negociaciones...», sino «Fulano, que había hecho...» En cuanto a el cual, usado sin preposición como explicativo, no debe mirarse siquiera como un relativo, sino como un demostrativo cualquiera: «dice que vive muy bien, lo cual me parece imposible», «por fin llegaron los viajeros que tanto habían tardado, los cuales, por cierto, ni siquiera poseían medios para sobrevivir».
} 
la subordinada. En efecto: en su estudio, Lope Blanch sólo cita dos ejemplos actuales de el cual, tomados, el primero, del habla de Santiago de Chile («tenemos... setenta y cinco mil personas a las cuales... se les ha seguido la historia»), y, el segundo, de la de Buenos Aires («con esa persona a la cual después con el tiempo le pedí disculpas»); y, sin embargo, ¿podrían realmente considerarse anómalos estos usos, cuando, incluso, en el primer ejemplo no hubiera sido admisible la construcción sin ese les?

No menciona Lope Blanch ejemplos modernos de quien, aun cuando, naturalmente, se dan («hay personas a quienes les gusta viajar»). De todos modos, los dos casos de «desdoblamiento» con quien, hallados por Juan Martínez Marín en La Celestina", están incomprensiblemente mal analizados, confundiendo la subordinada con la principal. Es cierto, en efecto, que en «a quien no me quiere no lo busco», lo posee el mismo referente que quien, pero no es menos cierto que ese lo no está en la misma oración, es decir, en la oración de relativo, sino en la principal «no lo busco», pues «a quien no me quiere» es sin duda la subordinada. Pero aunque la preposición corresponde sólo a la primera función del antecedente implícito, es decir, a la función con busco, no rige a quien, sino a ese antecedente que no se puede «reponer», porque la sintaxis de quien-y en eso se diferencia nítidamente de la de que - no admite «* no busco a la persona quien no me quiere» («no busco a la persona que no me quiere») ${ }^{12}$. Quien, con antecedente expreso, como se ha dicho, sólo puede aparecer con preposición, pero esa preposición, además, ha de corresponder necesaria y exclusivamente a la segunda función del antecedente, como en «tenía un hermano de quien no me había hablado». Si las funciones de ese antecedente expreso son dos y son preposicionales, aparecerán ambas marcas por su orden estricto: en «no conocía a la persona de quien me habías hablado», $a$ se refiere a la primera función (con conocía), y de, a la segunda (con habias hablado).

Así, pues, en el ejemplo de La Celestina, la preposición a pertenece al antecedente implícito, es decir, a la primera función, y no al relativo, que no es el complemento directo de busco, sino el determinante que reúne las incidencias de los dos verbos, subordinante y subordinado, y que, como cualquier relativo, pertenece sólo a la cláusula subordinada, pues a estos efectos se analizan de la misma manera

"Sintaxis de La Celestina, Universidad de Granada, 1978.

${ }^{12}$ Sin antecedente expreso, quien puede llevar una preposición relativa a la segunda función sólo en casos bien determinados, como cuando no depende directamente del verbo subordinante («se comportó como a quien correspondía»), que es lo que sucede cuando se construye con haber impersonal, en expresiones del tipo «no había a quien premiar», o en aquellas situaciones en las que los gramáticos lo clasifican como pronombre interrogativo, que es, sin duda, un uso de quien, pero no un quien diferente: «no sabe de quién quejarse», «ignoro con quién anda», etc. Lo que sucede en estos casos no es que el antecedente esté implícito o sobrentendido, sino, simplemente, que es desconocido. 
«no busco a la persona / que no me quiere», «no busco a la <------>/que no me quiere»y «no busco a <-------->/ quien no me quiere»,

sin necesidad, naturalmente, de suponer contenidos elípticos tras la o tras $a$. El objeto directo de busco está constituido por el antecedente «invisible», envuelto en quien, y toda la cláusula de relativo que lo especifica. Es evidente, en fin, que no existe ningún caso de lo que se ha llamado aqui despronominalización del relativo en el ejemplo «a quien no me quiere no lo busco», pues este lo no forma parte de la oración adjetiva, como ya he dicho más arriba. Y lo mismo sucede con el otro ejemplo, también de La Celestina, que cita Lope Blanch, tomándolo del mismo libro de Martínez Marín, si bien esta vez sin preposición: «quien no supiese mi nombre y mi casa, tenlo por extranjero». Es cierto que no hay preposición y que ésta sería preceptiva, al menos en el lenguaje cuidado, pero no lo es menos que esa preposición que «falta» corresponde al antecedente de quien, que, como todo relativo, pertenece por entero a la cláusula subordinada, en la que NO se encuentra el anafórico $l o$, es decir,

«ten(lo) por extranjero (a) $\longrightarrow$ /quien no supiese...», como

«ten(lo) por extranjero al <hombre> / que no supiese...»

Es correcto, en cambio, el ejemplo que Lope Blanch documenta en Ias cartas de Diego de Ordaz (op. cit.): «yo lo haré como a quien le toca».

En cuanto a cuyo, que es un relativo posesivo de tercera persona, posee un significado del tipo 'que su', como demuestran las combinaciones espontáneas destinadas a expresar esta doble relación de relativo y posesivo. Lope Blanch cita abundantes ejemplos de «duplicación» con $s u$ e, incluso, con el artículo: «... un edificio grande que su fachada está pintada de azul claro», «pero es un profesor que su palabra no llega a los estudiantes», etc. Sin embargo, no creo que deba hablarse en estos casos de «desdoblamiento del relativo cuyo», como hace Lope Blanch (op. cit.), dando por sentado que se «sustituye» cuyo por que $s u$ : «Ya en el Cantar de mio Cid - escribe- se halla algún testimonio: que su, por cuyo, es lo normal en el poema: "del Çid que su ondra creçe tanto"». Si es «lo normal», no se tratará justamente de la sustitución de la construcción «normal», ya que, además, el hablante no sustituye un relativo por otro, sino que elige, simplemente, una construcción con que (o con otro relativo), sin pensar en otra cosa. Con tan venerables antecedentes, ¿quién se habría atrevido a censurar a Cervantes si hubiese comenzado el Quijote diciendo «en un lugar de la Mancha que de su nombre no quiero acordarme»?

Gramaticalmente, de estas construcciones con posesivo o con otro determinante anafórico se puede decir lo mismo que de de las de que: la tendencia a funcionar como explicativas, aunque no son extrañas las especificativas, cuando no coincide la determinación del antecedente con la del determinante anafórico. 
Así, son especificativas «...un edificio grande que su fachada está pintada de azul claro», «...un profesor que su palabra no llega a los estudiantes», etc. Con antecedente identificador o identificado, la adjetiva es explicativa: «doña Luisa y don José, quien su abuelo (...) actuó como padrino», «llegamos a Angulema, que me encanta la catedral», etc. Pero no todos los ejemplos citados por Lope Blanch representan verdaderos «desdoblamientos» del relativo: en «... de la Empresa de Transportes X, cuyo Consejo de Administración lo preside el señor F.», está claro que lo no es una anáfora particular de cuyo, sino de todo el sintagma precedente Consejo de Administración, al que cuyo pertenece como determinante, de la misma manera que lo habría hecho $s u$, si se hubiera dicho «que su Consejo de Administración lo preside...», sin contar, por otra parte, con que ese lo nada tiene que ver con el antecedente del relativo la Empresa de Transportes $X$.

\section{En síntesis:}

1. No puede hablarse de despronominalización de los relativos cuando en la cláusula adjetiva aparezca un pronombre anafórico referido al antecedente,

1.1. porque los pronombres o determinantes, en primer lugar y como se ha visto, no sustituyen nada, sino que determinan algún contenido expreso o tácito, bien sea directamente, como si fueran adjetivos, bien sea anafóricamente (en «llamó a unas muchachas y se dirigió a la guapa», la se refiere anafóricamente a otro grado de determinación previo, representado por unas, y guapa, también anafóricamente, a muchachas), y

1.2. porque, en segundo lugar, no se «llenan» de contenido nominal, ya que ningún signo se puede llenar jamás del contenido de otro, en virtud del principio de la identidad funcional de todos los elementos de una lengua, cuyas unidades se definen, precisamente, por ser siempre lo que son. (Por eso, hablar de cambio de significado en los usos metafóricos es un disparate: nunca ha mantenido más nítido y claro su significado la palabra mariposa, que cuando la usa Góngora para aludir (no para significar, pues sólo puede significar lo que significa) a un leño en llamas: "yace la robusta encina, / mariposa en cenizas desatada»: la metáfora sólo lo es en virtud del principio de la identidad semántica de los signos, es decir, a condición de que no haya ningún cambio de significado.)

1.3. La aparición de un pronombre anafórico en la cláusula adjetiva, alusivo a la segunda función del antecedente, no altera la condición del relativo, que no pasa de una supuesta e hipotética condición «nominal» a otra supuesta y no menos hipotética condición «nexual». Que, como sus otros «cuasi-sinónimos», no es ni un nombre ni una conjunción, sino un determinante relativo, es decir, una partícula que acota un antecedente, vinculándolo a una estructura «consecuente»: se dice que encabeza cláusulas adjetivas cuando hace que el antecedente posea simultáneamente función sintáctica con los verbos subordinante y subordinado. 
1.4. La desvinculación entre antecedente y cláusula subordinada, producida por la presencia de algún pronombre anafórico alusivo a la segunda función del antecedente no cambia la naturaleza del relativo, que es invariable, pero puede alterar la naturaleza de la cláusula subordinada, como se ha visto.

1.5. Si no existe realmente despronominalización, no existe tampoco anomalía gramatical propiamente dicha, por lo que puede resultar fuera de lugar cualquier análisis estadístico o sociolingüístico de un fenómeno puramente imaginario, ya que su naturaleza real, como se ha visto, es muy otra. A veces la sociolingüística, con métodos estadísticos impecables, se pierde contando, midiendo o cuantificando hechos inexistentes o mal clasificados, por culpa de análisis lingüísticos previos deficientemente fundamentados. ¿De qué sirve, por ejemplo, la comparación del fenómeno por generaciones, como ha hecho el propio Lope Blanch ${ }^{13}$, si no sabemos exactamente qué estamos cuantificando? Es evidente, sin embargo, que con un correcto análisis gramatical del fenómeno, estaríamos en condiciones de examinar la dispersión social no ya de un fantasma inexistente, sino de las diferentes variedades de construcción que aquí hemos apuntado, distinguiendo entre las normales, que siguen viejas reglas de la gramática del español, y las «anómalas», con sus diversos grados de aceptabilidad.

2. La aparición de pronombres anafóricos alusivos al antecente de las subordinadas adjetivas entra en conflicto con el hecho de la bifuncionalidad del antecedente del relativo, que contrae relaciones simultáneas con los verbos subordinante y subordinado, por lo que

2.1. con frecuencia, se rompe el vínculo íntimo establecido entre ese antecedente y el verbo de la subordinada, de manera que ésta toma la estructura de una cláusula parentética en la que se sobrentiende un antecedente que ya no se siente como constituyente directo de ella. Aparecen así oraciones explicativas, que, con pronombre anafórico o no, quedan siempre fuera de la estructura de la principal, por lo que toman con facilidad otros valores contextuales adicionales, como el de causa.

2.2. Con todo, se mantiene con frecuencia el carácter especificativo de las cláusulas de relativo, tanto cuando el antecedente contrae con el verbo subordinado la función de objeto indirecto, como cuando contrae la de objeto directo, aunque en este último caso se requiere la existencia de una diferencia entre la determinación de la primera y de la segunda función del antecedente, pasándose de la indeterminación a la determinación («un secreto que no lo sabía nadie», frente a la explicativa, por ejemplo, «el secreto, que no lo sabía nadie»: no parece probable, más que en un contexto especialmente enfático, la especificativa «el secreto que no lo sabía nadie»).

"3 Cfr. «Duplicaciones pronominales en el habla culta de Madrid», en Estudios de lingüística española, Universidad Nacional Autónoma de México, 1986, pp. 137-143. 
El análisis semántico de los procesos gramaticales tiene la ventaja de sortear los problemas de sintaxis meramente distribucional y de verificar la naturaleza real de los signos, tanto léxicos como gramaticales. Frente a las estructuras distribucionales de las lenguas, están sus estructuras semántico-sintácticas, que, en muchos casos, como sucede con el de las cláusulas de relativo, no coinciden en absoluto entre sí. He pretendido aquí precisar la cuestión de la naturaleza semántica de los relativos, así como la de la escurridiza categoría tradicional del pronombre, y poner un poco de claridad, si es posible, en todas las también tradicionales confusiones entre la función anafórica y esa inexistente función «sustitutiva» que a tantos errores de bulto conduce en el análisis idiomático. En todo caso, nunca es esfuerzo perdido el de examinar los hechos de la lengua como son y no sólo como se han clasificado tradicionalmente (y como se siguen clasificando), tanto por influencia de la gramática del latín, como por su asimilación a una supuesta lógica que no es otra que la de la experiencia común de la realidad, que nada tiene que ver con la gramática, cuyo cometido es dar forma lingüística a cualquier cosa real o que se imagine como real, pero nunca el de reproducirla. 